\title{
ĐÁNH GIÁ KẾT QUẢ SAU PHẪU THUÂTT TRIỆT CĂN UNG THƯ HẮC TỐ DA GIAI ĐOẠN II, III TẠI BỆNH VIỆN K
}

\author{
Vũ Thanh Phương*, Vũ Hồng Thăng*, Nguyễn Đại Bình*
}

\section{TÓM TẮT}

Mục tiêu: nhận xét đặc điểm lâm sàng và kết quả sau phẫu thuật triệt căn đơnn thuân UTHT da giai đoạn II, III. Đối tượng, phương pháp: mô tả tiến cứu và hối cứu 130 bệnh nhân UTHT da giai đoạn II, III được điều trị bằng phẫu thuật tại viện $\mathrm{K}$ từ 2013-2019. Kềt quả:bệnh hay gặp từ 40 đến 79 tuổi, tuổi TB 56,0 \pm 1,8 , thấp nhất 18 và cao nhất 85 , nam/nữ là 1,03 . Vị trí hay gặp chi dưới $46,9 \%$, u màu đen $69,9 \%$, thay đổi kích thước hình dạng u $100 \%$, u trên nền da dây sừng hóa $42,3 \%$, vệ tinh $23,8 \%$, loét u $31,6 \%$. Di căn hach khu vức 48,5\%, giai đoan 2,3 là $43,1 \%, 56,9 \%$. Cẳt rộng u, vét hạch khu vực 83,8\%; cắt cụt chi, tháo khớp, vét hạch khu vực 16,2\%. Tạo hình sau cắt u bằng vạt da cơ có cuống mạch nuôi $13,8 \%$, vạt da hoán vị $7,7 \%$ và vá da rời $7 \%$. Biến chứng phù bạch mạch sau vét hach khu vực $11,5 \%$, tái phát u và hạch khu vực $9,2 \%$. Di căn xa sau điêu trị $51,5 \%$, trong đó di căn phổi, gan, não, dưới da và đa tạng tương ứng là $50,7 \%, 10,5 \%, 13,4 \%, 6 \%$ và $19,4 \%$. Tỷ lệ sống thêm không bênh $1,3,5$ năm tương ứng là $93,8 \%$, $65,9 \%$ và $40,7 \%$. Sống thêm toàn bộ $1,3,5$ năm là $100 \%, 73,1 \%$ và $47,1 \%$. Sống thêm toàn bộ 5 năm giai đoạn 2, 3 là 75,3\% và 28\%. Kết luận: Bệnh hay gặp: trền 40 tuổi, vị trí chi dưới, u màu đen loang lô, thay đổi kích thước hình dạng, trên nền da dây sừng hóa. Tỷ lệ nam / nữ là 1,03, vệ tinh quanh u 23,8\%, loét u $31,6 \%$. Di căn hach khu vực $48,5 \%$, giai đoăn 2,3 tương ứng là $43,1 \%, 56,9 \%$. Kết quả sau phẩu thuật cắt rộng u, vét hạch khu vực 83,8\%; cắt cụt chi, tháo khớp, vét hach khu vực 16,2\%. Tao hình khuyết hổng sau cắt u bằng vạt da cớ có cuổng mạch nuôi $13,8 \%$, vạt da hoán vị $7,7 \%$ và vá da rời $7 \%$. Biến chứng phù bạch mạch sau vét hạch khu vực 11,5\%, tái phát u và hạch khu vực $9,2 \%$. Di căn xả sau điêu trị 51,5\%.Tỷ lệ sống thểm không bệnh sau 1, 3, 5 năm tương ứng là $93,8 \%, 65,9 \%$ và $40,7 \%$. Sống thêm toàn bộ sau $1,3,5$ năm là $100 \%, 73,1 \%$ và $47,1 \%$. Sống thêm toàn bộ sau 5 năm giai đoạn 2,3 là $75,3 \%$ và $28 \%$. thuật

Tư khóa: ung thư hắc tố da, kết quả sau phẫu

\section{SUMMARY}

EVALUTERESULTS AFTER SURGERY OF STAGE II, III CUTANEOUS MELANOMA AT K HOSPITAL

Objective: Study on clinical features andresults after adical surgery alone of stage II, IIIcutaneous melanoma. Subjects and methods: A retrospective

\section{*Bênh viên $K$}

Chịu trách nhiệm chính: Vũ Thanh Phương

Email: vuthanhphuonghm@gmail.com

Ngày nhận bài: 12/10/2021

Ngày phản biên khoa họ: 5/11/2021

Ngày duyệt bài: 22/11/2021 and prospective study on 130 cutaneous melanoma patients in stage II, III were treated with surgery at K hospital from 2013 to 2019. Results: The average age is $56,0 \pm 1,8$, which is common from 40 to 79 years old, youngest patient 18 year-old and the oldest one 85 year-old, male/female 1,03 . Tumors are often located in the lower limbs $46,9 \%$, black tumor $69.9 \%$, change in size, shape $100 \%$, tumors grow on thick skin $42,3 \%$, satellite $23,8 \%$, ulcer $31,6 \%$. Regional lymph node positive $48,5 \%$, stage 2,3 are $43,1 \%, 56,9 \%$. Wide excision, lymphadenectomy $83,8 \%$; amputation, disassembling, lymphadenectomy $16,2 \%$. Reconstruction after tumor resection by skin flap with vascular $13,8 \%$, permuted skin flap $7,7 \%$ and skin patch 7\%. Lymphedema after lymphadenectomy $11,5 \%$, recurrenced tumor and regional lympho node $9,2 \%$. Distant metastasis after treatment $51,5 \%$, lung metastasis $50,7 \%$, liver metastasis $10,5 \%$, brain metastasis $13,4 \%$, subcutaneous metastasis $6 \%$ and multi-organ metastasis $15.9 \%$. The $1,3,5$ years disease-free survival is $93,8 \%, 65,9 \%$ and $40,7 \%$, respectively. The $1,3,5$ years overall survivalis $100 \%$, $73,1 \%$ and $47,1 \%$, respectively. The 5 -yearsoverall survival in stages 2, 3 is $75,3 \%, 28 \%$. Conclusion: Cutaneous melanoma is common: > 40 years old, lower limbs, black tumor, change in size, shape, grow on thick skin. Male/female 1,03 , satellite $23,8 \%$, ulcer $31,6 \%$. Regional lymph node positive $48,5 \%$, stage 2 , 3 are $43,1 \%, 56,9 \%$. Results after surgery: wide excision, lymphadenectomy 83,8\%; amputation, disassembling, lymphadenectomy $16,2 \%$. Reconstruction after tumor resection by skin flap with vascular $13,8 \%$, permuted skin flap $7,7 \%$ and skin patch 7\%. Lymphedema after lymphadenectomy $11,5 \%$, recurrenced tumor and regional lympho node $9,2 \%$. Distant metastasis after treatment $51,5 \%$. The $1,3,5$ years disease-free survival is $93,8 \%, 65,9 \%$ and $40,7 \%$, respectively. The $1,3,5$ years overall survival is $100 \%, 73,1 \%$ and $47,1 \%$, respectively. The 5 -years overall survival in stages 2, 3 is $75,3 \%, 28 \%$.

Keywords: Cutaneous melanoma, results after surgery

\section{I. ĐĂT VẤN ĐỀ}

Ung thư hắc tố (UTHT) da là bệnh lý ác tính của các tế bào sinh sắc tố melanin ở da. Các tế bào này phân bố chủ yếu ở lớp đáy của thượng bì (90\%), niêm mạc, màng não, võng mạc mắt, sinh dục, đại trực tràng, ông hậu môn. UTHT da là bệnh rất ác tính, tiến triển nhanh, di căn sớm [1]. Tỷ lệ mắc UTHT da tăng liên tục ở hâu hết các nước trong nhiều thập kỷ qua, có xu hướng thành bệnh phổ biến ở các nước châu Âu, châu Mỹ, Úc và Newzealand. Tại Mỹ, theo hiệp hội ung thư Hoa Kỳ,2020 có 100.350 ca mắc mới trong đó 60.190 nam, 40.160 nữvà 6.850 ca tử 
vong do bệnh này trong đó 4.610 nam và 2.240 nữ. Là bệnh phổ biến thứ năm ở nam giới và thứ 6 ở nữ giới, là một trong những ung thư phát triển nhanh nhất trong các bệnh ung thư ở Mỹ [2], [3]. Ở Việt Nam, nhiều năm gần đây, chưa có công bố cụ thể về tỷ lệ mắc và tử vong UTHT da, theo ghi nhâan của Phạm Hoàng Anh năm 1993, tỷ lệ mắc là 0,3-0,4/100.000 dân. UTHT da là bệnh ít gặp, nhưng đến khám và điều trị tại bệnh viện $\mathrm{K}$ tăng lên hàng năm. Do hiểu biết về bểnh này còn hạn chế nên trên $80 \%$ bệnh nhân đến khám ở giai đoạn II, III [4],[5]. Điểutrị hiện nay, phẫu thuật là phương pháp điều trị chủ yểu khi bệnh ở giai đoạn tại chố, tại vùng, phương pháp điều trị bằng hóa chất kém hiệu quả, mang tính chất điêu trị triệu chứng khi bệnh ở giai đoạn muộn. Trong nước, hai thập kỷ qua chưa có nghiên cứu nào về đánh giá kết quả điều trị ung thư hắc tố da. Vậy chúng tôi tiến hành nghiên cứu đề tài "Đánh giá kết quả sau phẫu thuật triệt căn UTHT da giai đoạn II, III tại bệnh viện $\mathrm{K}^{\prime \prime}$ nhằm 2 mục tiêu:

- Mô tả một số đặc điểm lâm sàng ung thư hắc tố da

- Đánh giá kêt quả sau phẫu thuật triệt căn đơn thuần ung thư hắc tố da giai đoạn II, III.

II. ĐỐI TƯợNG VÀ PHƯƠNG PHÁP NGHIÊN CỨU

2.1. Đối tượng nghiên cứu: 130 bệnh nhân UTHT da giai đoạn II, III, được điêu trị bằng phẫu thuật triệt căn đơn thuần tại bệnh viện K từ 2013-2019.

- Tiêu chuẩn lựa chọn: Bệnh nhân bị UTHT da giai đoạn II, III, được chẩn đoán xác định là UTHT da bằng mô bệnh hơc tại viện $\mathrm{K}$, còn khối u nguyên phát chưa phẩu thuật tuyến dưới, được điều trị bằng phẫu thuật triệt căn, có đủ hố sơ bệnh án lưu trữ, không mắc các bệnh mạn tính khác có nguy cơ tử vong gần, không mắc các bệnh ung thư khác.

- Tiêu chuẩn loại trừ: Tất cả các trường hợp không đủ tiêu chuẩn trên.

Cõ̃ mấu, chọn mẫu: Cỡ mẫu 130 trường hợp (hồi cứu 28, tiến cứu 102), chọn mẫu toàn bộ, có chủ đích.

2.2. Phương pháp nghiên cứu: Mô tả hồi cứu và tiến cứu.

2.3. Các biến số, chỉ số: Nhóm tuổi< 20 , 20-39, 40-59, 60-79, $\geq 80$ tuổi, giới nam, nữ.Vị trí u đầu cố, thân mình, chi trên, chi dưới. Màu sắc đen, nâu sẫm, không sắc tố. Thay đổi kích thước hình dạng, hình thái loét, sùi, nốt ruồi to, phẳng. Nền u da thường, nốt ruồi, da dây sừng, sắc tố bẩm sinh, vệ tinh, loét u, hạch khu vực, giai đoạn bệnh 2,3, phương pháp mổ cắt rộng u vét hạch khu vực, cắt cụt chi, tháo khớp chi vét hach khu vực, mô bệnh học diện cắt u, tạo hình bằng vạt da cơ có cuống mạch nuôi, vạt da hoán vị, vá da rời. Biến chứng sau mổ nhiễm trùng, chảy máu, hoại tử vạt da, phù bạch huyết. Tái phát $u$, hạch khu vực sau điều trị, di căn phổi, gan, não, dưới da, đa tạng.

2.4. Quy trình nghiên cứu: Thu nhập đăc điểm lâm sàng qua trực tiếp khám bệnh nhân lúc vào viên đối với nhóm tiến cứu, khai thác hồ sơ bệnh án đối với nhóm hồi cứu, làmxét nghiệm cận lâng sàng để phân giai đoạn bệnh theo AJCC 2009 vào bệnh án nghiên cứu mẫu. Mổ cắt rộng u hoặccắt cụt, tháo khớp chi, vét hạch khu vực cho các trường hợp, theo dõi các biến chứng sau mổ. Làm mô bệnh học và hóa mô miễn dịch để chẩn đoán và đặc điểm $u$ : bề dày $u$, nhân vê tinh, loét $u$, tỷ lệ nhân chia, số hạch di căn để phân giai đoạn TNM. Theo dõi tái phát u, hạch, di căn xa và sống thêm bằng hẹn bệnh nhân khám định kỳ, gửi thư, gọi điện thoại, tính tỷ lệ sống thêm $1,3,5$ năm không bệnh, toàn bộ và theo giai đoạn bênh.

2.5.Xử lý số liệu: Sử dụng phần mềm SPSS 20.0 để nhập và phân tích số liệu, tính tần suất, tỷ lệ phần trăm.Tính tỷ lệ sông thêm theo sự kiện Kaplan - Meier.

2.6. Thời gian, địa điểm nghiên cứu: Từ 1/1/2016 đến 20/11/2021, bệnh viện $K$.

2.7. Đạo đức nghiên cứu: Đề cương nghiên cứu đã được hội đồng đạo đức trường Đai học Y Hà Nội phê duyệt. Tất cả biến số, chỉ số nghiên cứu được thu thập một cách trung thực và khoa học.

\section{KẾT QUẢ NGHIÊN CỨU}

\section{1.Đăc điểm lâm sàng}

Bảng 1. Đặc điểm lâm sàng $(n=130)$

\begin{tabular}{|c|c|c|}
\hline Nhóm tuối & Số BN & Tỷ lệ \% \\
\hline$<20$ & 1 & 0,5 \\
\hline $20-39$ & 14 & 11,1 \\
\hline $40-59$ & 64 & 53,1 \\
\hline $60-79$ & 47 & 30,4 \\
\hline$\geq 80$ & 4 & 4,9 \\
\hline Giới: & 66 & 50,7 \\
\hline Nữ & 64 & 49,3 \\
\hline Vị trí u: Đầu cố & 19 & 14,6 \\
\hline Thân mình & 29 & 22,3 \\
\hline Chi trên & 21 & 16,2 \\
\hline Chi dưới & 61 & 46,9 \\
\hline \multicolumn{3}{|c|}{ Mâu săc u } \\
\hline Đen tuyền loang lố & 87 & 66,9 \\
\hline Nâu sâm & 35 & 26,9 \\
\hline Không nhiêm sắc & 8 & 6,2 \\
\hline
\end{tabular}




\begin{tabular}{|c|c|c|}
\hline \multicolumn{3}{|c|}{ Thay đối kt, hình dạng u } \\
\hline Có & 130 & 100 \\
\hline Không & 0 & 0 \\
\hline Hình thái u: Loét & 16 & 12,4 \\
\hline Loét sùi & 25 & 19,2 \\
\hline Nốt ruôi to & 51 & 39,2 \\
\hline Sùi & 26 & 20 \\
\hline Phằng & 12 & 9,2 \\
\hline \multicolumn{3}{|c|}{ Nền u } \\
\hline Da thường & 19 & 14,6 \\
\hline Nốt ruôi & 52 & 40 \\
\hline Da sừng hóa & 55 & 42,3 \\
\hline Sắc tố bấm sinh & 4 & 3,1 \\
\hline \multicolumn{3}{|c|}{ Vệ tinh quanh u } \\
\hline Có & 31 & 23,8 \\
\hline Không & 99 & 76,2 \\
\hline \multicolumn{3}{|c|}{ Hạch khu vực } \\
\hline Chưa di căn & 67 & 51,5 \\
\hline Di căn 1 hạch & 20 & 15,4 \\
\hline Di căn 2 -3 hạch & 18 & 13,9 \\
\hline Di căn > 3 hạch & 25 & 19,2 \\
\hline \multicolumn{3}{|c|}{ Giai đoạn } \\
\hline Giai đoạn 2 & 56 & 43,1 \\
\hline Giai đoạn 3 & 74 & 56,9 \\
\hline
\end{tabular}

Tuổi trung bình là $56,0 \pm 1,8$, thấp nhất 18 và cao nhất 85; độ tuổi hay gặp từ 40 đến 79 tuổi $83.5 \%$, nam/nữ là 1.03 , vị trí gặp nhiêuu ở chi dưới 46,9\%, màu đen gặp nhiều 66,9,\%. Thay đổi kích thước hình dạng u 100\%, loét + loét sùi $31,6 \%$. U xuất hiện trên da dây sừng hóa $42,3 \%$, có vệ tinh $23,8 \%$, chưa di căn hạchkhu vực $51,5 \%$. Giai đoạn 2,3 là 43,1\% và $56,9 \%$.

3.2. Kết quả sau phẫu thuật triệt căn UTHT da giai đoạn 2, 3

3.2.1. Phương pháp mổ, diện cắt $u$, tạo hình, biến chứng, tái phát u hạch, di căn xa

Bảng 2. Phương pháp mô, diện cắt $u$, tạo hình, biến chứng, tái phát, di căn xa

\begin{tabular}{|c|c|c|}
\hline $\begin{array}{c}\text { Phương pháp mố } \\
\text { (n= 130) }\end{array}$ & Số BN & $\begin{array}{c}\text { Tỷ lệ } \\
\mathbf{\%}\end{array}$ \\
\hline Cắt rộng khối u + vét hạch khu vực & 109 & 83,8 \\
\hline
\end{tabular}

\begin{tabular}{|c|c|c|}
\hline $\begin{array}{l}\text { Cắt cụt chi, tháo khớp bàn ngón + } \\
\text { vét hạch khu vực }\end{array}$ & 21 & 16,2 \\
\hline $\begin{array}{l}\text { Mô bệnh học diệ̂ cắt u } \\
\qquad(n=124)\end{array}$ & Số BN & \\
\hline Còn ung thư & 0 & 0 \\
\hline Không còn ung thư & 124 & 100 \\
\hline $\begin{array}{l}\text { Tạo hình khuyết hổng } \\
(\mathbf{n}=130)\end{array}$ & Số BN & \\
\hline không tạo hình & 93 & 71,5 \\
\hline vạt da cơ có cuống mạch nuôi & 18 & 13,8 \\
\hline vạt da hoán vị & 10 & 7,7 \\
\hline vá da rời & 9 & 7 \\
\hline Biến chứng sau mố( $n=130)$ & Số BN & \\
\hline Không biến chứng & 112 & 86,2 \\
\hline Nhiềm trùng vết mố & 2 & 1,5 \\
\hline Chảy máu vết mố & 1 & 0,8 \\
\hline Phù bạch mạch sau vét hạch & 15 & 11,5 \\
\hline Hoại tử vạt da & 0 & 0 \\
\hline $\begin{array}{l}\text { Tái phát u, hạch khu vực } \\
(\mathbf{n}=130)\end{array}$ & Số BN & \\
\hline Không tái phát & 118 & 90,8 \\
\hline Tái phát & 12 & 9,2 \\
\hline Di căn xa (n = 67) & Số BN & \\
\hline Phối & 34 & 50,7 \\
\hline Gan & 7 & 10,5 \\
\hline Não & 9 & 13,4 \\
\hline Dưới da & 4 & 6 \\
\hline Đa tang & 13 & 19,4 \\
\hline
\end{tabular}

Cắt rộng u và vét hạch khu vực chiếm 83,8\%, có 124 trường hợp làm giải phẫu bệnh diện cắt u đều không còn tế bào ung thư (100\%). Tạo hình khuyết hổng sau cắt u bằng vạt da cơ có cuống mạch nuôi $13,8 \%$, vạt da hoán vị $7,7 \%$ và vá da rời $7 \%$. Phù bạch mạch sau vét hạch khu vực $11,5 \%$, tái phát u, hạch khu vực 9,2\%. Di căn xa sau điều trị $67 \mathrm{TH}(51,5 \%)$, trong đó di căn phổi, gan, não, dưới da và đa tạng tương ứng là $50,7 \%, 10,5 \%, 13,4 \%, 6 \%$ và $19,4 \%$.

3.2.2. Tỷ lệ sống thêm 1, 3, 5 năm khộng bệnh, toàn bộ và giai đoạn bệnh sau phẫu thuật triệt căn $(\mathbf{n}=130)$

Bảng 3. Sông thêm 1, 3, 5 năm không bệnh, toàn bộ và giai đoạn 2, 3

\begin{tabular}{|c|c|c|c|c|}
\hline Theo dõi & $\begin{array}{c}\text { BN không } \\
\text { TPDC }\end{array}$ & BN TPDC & Mất theo dõi & $\begin{array}{c}\text { Sống thêm } \\
\text { Kaplan-Meier }\end{array}$ \\
\hline 1 năm không bệnh & 122 & 8 & 0 & 93,8 \\
\hline 3 năm không bệnh & 79 & 51 & 0 & 65,9 \\
\hline 5 năm không bệnh & 63 & 67 & 0 & 40,7 \\
\hline Theo dõi & BN sống & BN chết & Mất theo dõi & $\begin{array}{c}\text { Sống thêm } \\
\text { Kaplan-Meier }\end{array}$ \\
\hline 1 năm toàn bộ & 130 & 0 & 0 & 100 \\
\hline 3 năm toàn bộ & 98 & 32 & 0 & 73,1 \\
\hline 5 năm toàn bộ & 80 & 50 & 0 & 47,1 \\
\hline Giai đoạn & BN sống & BN chết & Số BN & Sống thêm \\
\hline
\end{tabular}




\begin{tabular}{|c|c|c|c|c|}
\hline & & & & Kaplan-Meier \\
\hline Giai đoạn 2 & 51 & 5 & 56 & 75 \\
\hline Giai đoạn 3 & 29 & 45 & 74 & 28 \\
\hline
\end{tabular}

Tỷ lệ sống thêm không bệnh 1, 3, 5 năm tương ứng 93,8\%,65,9\% và 40,7\%. Sống thêm toàn bộ 1, 3, 5 năm tương ứng 100\%, 73,1\% và 47,1\%.Sống thêm toàn bộ 5 năm giai đoạn 2, 3 là 75,3\% và 28\%.

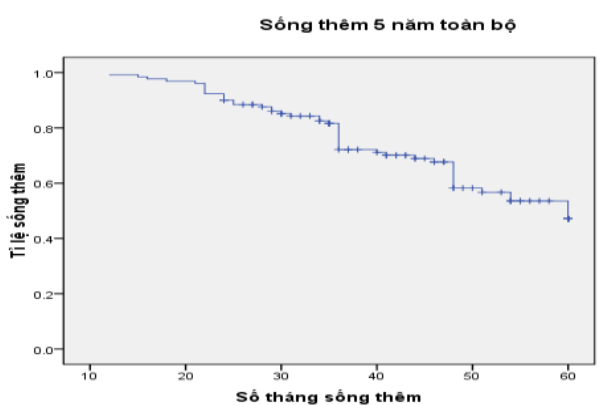

Biểu đồ 1. Sống thêm 5 năm không bệnh

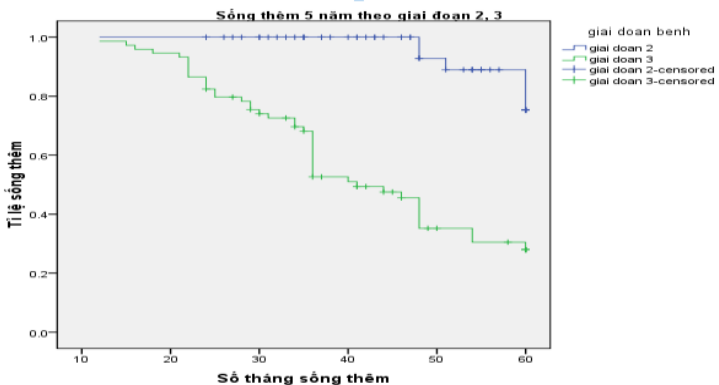

Biểu đồ 2. Sống thêm toàn bộ 5 năm theo giai đoạn 2, 3

\section{BÀN LUẬN}

\section{1. Đăc điểm lâm sàng}

4.1.1.Tuổi, giới: Tuổi trung bình là $56,0 \pm 1,8$, trẻ nhất 18 tuổi, già nhất 85 tuổi, nhóm gặp nhiêuutừ 40 đến 79 tuổi chiếm $83,5 \%$.Tỷ lê nam/nữ là 1,03 . Kết quả này tương tự kết quả của Đào Tiến Lục, tuổi trung bình là 55,4 , nhóm hay gặp 40 đến 80 là $84,8 \%$, tỷ lệ nứ/ nam là 1,24 . Kết quả nghiên cứu của Masback $A$, tuổi trung bình là 53,2 , trẻ nhất 12 tuổi, già nhất 86 tuổi; nhóm hay gặp 50 đến 80 là 76,6\%, tỷ lệ nữ/ nam 1/2[5],[6].

4.1.2. Vị trí, mâu sắc u: Nghiên cứu của chúng tôi hay gặp ở chi dưới46, $9 \%$, chi trên $16,2 \%$, thân mình $22,3 \%$ và đầu cổ $14,6 \%$. Màu đen $69,9 \%$, nâu sẫm $26,9 \%$, không nhiễm sắc $6,2 \%$. Kết quả này tương tự nghiên cứu của Đào Tiến Lục, có $50,4 \%$ gặp ở chi dưới, 17,9\% ở chi trên, $16,6 \%$ ở thân mình, $14,7 \%$ ở đầu cổ, mầu đen $55 \%$, nâu sẫm $29,5 \%$, không nhiễm sắc $15,5 \%$. Nghiên cứu của chúng tôi vị trígặp ở chi dướitỷ lê cao hơn kết quả của Masback $A$ là $34,9 \%[5]$, [6]. Sự khác nhau này có thể do bệnh nhân thuộc chủng tộc và địa lý khác nhau.

\subsubsection{Thay đổi kích thước, hình dạng u:}

Nghiên cứu của chúng tôi tất cả khối u đều có thay đổi kích thước hình dạng (100\%), Hình thái loét và loét sùi 31,6 , nốt ruồi to $39,2 \%$. Sùi và phẳng là $20 \%, 9,2 \%$. Kết quả này tương tự kết quả của Đào Tiền Lục, loét và loét sùi là 39,7 và nốt ruồi to $42,6 \%$, sùi đơn thuần $12,4 \%$, khác với kết quả của Masback $A$, với loétđơn thuần và thể loét sùi $26,2 \%$ [5], [6]. Sư khác nhau này có thể bệnh nhân của chúng tôi được phát hiện muộn hơn, nên tỷ lệ thể loét, loét sùi cao hơn.

4.1.4. Nền u, vệ tinh quanh u: Nghiên cứu của chúng tôi $\mathrm{u}$ xuất hiện trên da sừng hóa $42,3 \%$, nốt ruồi $40 \%$, da thường $14,6 \%$.Khối u xuất hiện nhiều trên nền da sừng hóa như gan bàn tay, gan bàn chân đặc biệt ở gót chân.Có nhân vê tinh $23,8 \%$. Kết quả của Đào Tiến Lục, u xuất hiện trên da sừng hóa là $50,3 \%$, trên nốt ruồi 38,6\%, nhân vệ tịnh quanh u là 23,4\%.Kết quảnghiên cứu của Masback $A, u$ trên da sừng hóa 40,6\%, vệ tinh quanh u là 6,04\%[5], [6],kết quả của chúng tôi tỷ lệ nhân vệ tinh cao hơn là do bệnh nhân của chúng tôi thường đến viện chủ yểu là giai đoan 3 .

4.1.5. Di căn hạch, giai đoạn 2, 3: Nghiên cứu của chúng tôi di căn hạch khu vực là 48,5\%, chưa di căn hạch $51,5 \%$, giai đoạn 2, 3 tương ứng là $43,1 \%$ và $56,9 \%$. Kết quả nghiên cứu của Đào Tiến Lục di căn hach khu vực là $57,2 \%$, giai đoạn 2,3 tương ứng là $39,4 \%$ và $57,2 \%$. Kết quả của chúng tôi cao hơn so với nghiên cứu của Masback A di căn hạch khu vực chỉ có $18,8 \%$ và giai đoạn 3chỉ 18,8\% [5], [6]. Nguyên nhân là bệnh nhẩn của chúng tôi thường đến viện ở giai đoạn 3 , đó là giai đoạn đã có sự di căn hạch khu vực.

\subsection{Kết quả sau phẫu thuật triệt căn} UTHT da giai đoạn 2, 3

4.2.1.Phương pháp mổ, mô bệnh học diện cắt $u$, tạo hình, biến chứng, tái phát, di căn xa: Nghiên cứu của chúng tôicắt rộng khốiu và vét hạch khu vực chiếm $83,8 \%$, cắt cụt chi, tháo khớp bàn ngón và vét hạch khu vực $16,2 \%$. Có 124 trường hợp làm xét nghiệm giải phẫu bệnh diện cắt $u$ đều không còn tế bào ung thư (100\%). Tạo hình khuyết hổng sau cắt u bằng vạt da cơ có cuống mạch nuôi $13,8 \%$, bằng vạt da hoán vị $7,7 \%$, vá da rời $7 \%$ và không phải tạo hình $71,5 \%$. Biến chứng phù bạch mạch là $11,5 \%$. Tái phát tại u, hạch khu vực $9,2 \%$. Di căn xa sau điều trị $51,5 \%$, trong đó di căn phổi, gan, 
não, dưới da và đa tạng tương ứng là $50,7 \%$, $10,5 \%, 13,4 \%, 6 \%$ và $19,4 \%$. Kết quả nghiên cứu của Đào Tiến Lục cắt rộng u và vét hạch khu vực $80,4 \%$, cắt cụt chi, tháo khớp bàn ngón và vét hạch khu vực 19,6\%, biến chứng phù bạch mạch sau vét hạch khu vực $16,8 \%$, tái phát tại u, hạch khu vực 25,6\%, di căn xa sau mổ 54,5\% [5]].

4.2.2. Sống thêm $1,3,5$ năm không bệnh, toàn bộ và theo giai đoạn 2, 3: Tỷ lệ sổng thêm khổng bệnh $1,3,5$ nẳm tương ứng $93,8 \%, 65,9 \%$ và $40,7 \%$. Sống thêm toàn bộ 1 , 3,5 năm tương ứng $100 \%, 73,1 \%$ và $47,1 \%$. Sống thêm toàn bộ 5 năm giai đoạn 2,3 là $75,3 \%$ và $28 \%$. Kết quả nghiên cứu của chúng tôi cao hơn của Đào Tiến Lục trên 157 bệnh nhân sống thêm toàn bộ sau 5 năm là $24,6 \%$ cho giai đoạn 2,3 sau phẫu thuật, sống thêm 5 năm toàn bộ sau phẫu thuật của giai đoạn 2,3 tương ứng là $59 \%$ và $12,5 \%$.

\section{KẾT LUẬN}

\section{1. Đặc điểm lâm sàng}

- Bệnh hay gặp: trên 40 tuổi, vị trí chi dưới, u màu đen loang lổ, thay đổi kích thước hình dạng, trên nền da dây sừng hóa.

- Tỷ lệ nam / nữ là 1,03, vệ tinh quanh u $23,8 \%$, loét u $31,6 \%$. Di căn hạch khu vực $48,5 \%$, giai đoạn 2, 3 tương ứng là 43,1\%, 56,9\%.

\subsection{Kết quả sau phẫu thuật triệt căn}

- Cắt rộng u, vét hạch khu vực 83,8\%; cắt cụt chi, tháo khớp, vét hạch khu vực 16,2\%. Tạo hình khuyết hổng sau cắt $u$ bằng vạt da cơ có cuống mạch nuôi $13,8 \%$, vạt da hoán vị $7,7 \%$ và vá da rời $7 \%$.
- Biến chứng phù bạch mạch sau vét hạch khu vực $11,5 \%$, tái phát u và hạch khu vực $9,2 \%$. Di căn xa sau điều trị $51,5 \%$, trong đó di căn phổi, gan, não, dưới da và đa tạng tương ứng là $50,7 \%, 10,5 \%, 13,4 \%, 6 \%$ và $19,4 \%$.

- Tỷ lệ sống thêm không bệnh sau 1, 3, 5 năm tương ứng là $93,8 \%, 65,9 \%$ và $40,7 \%$. Sống thêm toàn bộ sau $1,3,5$ nămlà $100 \%, 73,1 \%$ và $47,1 \%$. Sống thêm toàn bộ sau 5 năm giai đoạn 2,3 là $75,3 \%$ và $28 \%$.

\section{TÀI LIÊU THAM KHẢO}

1. Albino A.P, Reed J.A., McNutt N.S et al. (1997). Molecular Biology of Cutaneous Melanoma, Principles and practice of Oncology. Lippincott Raven, 2, 46.

2. Cutaneous melanoma: Etiology and therapy (2017). Chapter 1: Epidemiology of melanoma. Brisbane (AU): Codon Publications.

3. Marc Hurlbert (2020). 2020 Melanoma mortality rates decreasing despite ongoing increase in incidence. Melanoma research Alliance.

4. Phạm Hoàng Anh và cộng sự (1993), Ung thư Hà Nội 1991-1992, y học Việt Nam; chuyên đề ung thưư tập 173, số 7, 14-21.

5. Đào Tiến Lục (2001), Nghiên cứu đă̆c điểm lâm sàng, mô bểnh học và một số yếu tổ tiên lượng của ung thư hắc tố. Luận văn bác sỹ nội trú, trường đại học $Y$ Hà Nội.

6. Masback $\dot{A}$, Westerdahl J, Ingvar et al. (1997). Cutaneous malignant melanoma in southern Sweden 1965, 1975 and 1985 prognostic factors and histologic correlations.Cancer, 83, 275-83.

7. Barnhill RL, Fine JA, Roush GC, Berwick M. (1996). Predicting five-year outcome for patients with cutaneous melanoma in a population-based study. Cancer, 78, 427-432.

\section{ĐĂC ĐIỂM LÂM SÀNG CỦA BÊ̂NH NHÂN BỤI PHỔI SILIC ĐIỀU TRI TẠI BỆNH VIỆN PHỔI TRUNG ƯO'NG, NĂM 2019-2020}

\section{Nguyễn Ngọc Anh, Lê Thị Thanh Xuân, Lê Thị Hương, Phậm Thị Quân, Nguyễn Thị Quỳnh(*)}

\section{TÓM TẮT}

Bệnh bụi phổi silic cho đên hiện nay chưa có thuốc điều trị đặc hiệu, người bệnh thường vào viện điêu trị bởi những ảnh hưởng của bệnh lên cơ quan hô hấp với các triệu chứng không khác biệt so với các bệnh hô hấp thông thường khác. Nhằm giúp cho các bác sỹ

(*)Viện ĐT YHDP \& YTCC, Đại học Y Hà Nội

Chịu trách nhiệm chính: Nguyễn Ngọc Anh

Email: anhnn@hmu.edu.vn

Ngày nhận bài: 13.9.2021

Ngày phản biện khoa học: 8.11.2021

Ngày duyệt bài: 15.11.2021 lâm sàng có những nhìn nhận về bụi phổi silic một cách rõ ràng hơn, từ đó giúp cho hướng chẩn đoán bệnh sớm, một nghiên cứu hồi cứu mô tả các triệu chứng lâm sàng thu nhận được ở 103 bênh nhân bụi phổi silic được điều trị tại Bệnh viện Phổi trung ương năm 2019-2020. Kết quả cho thấy: $98 \%$ bệnh nhân bụi phổi silic điều trị tại Bệnh viện Phổi trung ương là nam giới; $33,7 \%$ lao động khai thác vàng; 25,5\%khai thác đá. Khó thở là triệu chứng cơ năng thướng gặp nhất $(98,8 \%)$. Triệu chứng thực thể: Rì rào phế nang giảm chiếm $91,2 \%$, rale nổ là $75,7 \%$, rale ẩm là $73,8 \%$. Cần khai thác tiền sử nghề nghiệp để có thể chẩn đoán sớm bệnh bụi phổi silic tại các cơ sở điều trị bệnh hô hấp. Cần thực hiện giám sát phát hiện và 